\title{
Article
}

\section{Characterization of Tool Degradation during Friction Stir Processing of 6061-T6 Aluminum Alloy Extrusions}

\author{
Nelson Netto ${ }^{1}$, Murat Tiryakioğlu ${ }^{1, *}$ and Paul D. Eason ${ }^{1}$ \\ 1 School of Engineering \\ University of North Florida \\ Jacksonville, FL 32224 USA \\ * Correspondence: m.tiryakioglu@unf.edu; Tel.: +1-904-620-1390
}

\begin{abstract}
The diameter of a H13 steel tool with M6 threads and a pin diameter of $5.9 \mathrm{~mm}$ and a pin length of $5 \mathrm{~mm}$ was measured after each $25.4 \mathrm{~mm}$ length of friction stir processing (FSP) of 6061-T6 extrusions. The change in pin diameter with FSP time or distance did not exhibit any steady state and was found to have two distinct regions. Metallographic analysis of two tools subjected to FSP for 60 and 120 seconds showed that (i) threads fractured in early stages of FSP, (ii) a built-up layer formed between the threads, and (iii) threads progressively wore with processing time. The metallographic analysis of an embedded tool showed the presence of a fractured piece of the tool in the stir zone. These points are discussed in detail in the paper.
\end{abstract}

Keywords: Thread fracture; tool wear; Taylor Equation; Scanning Electron Microscopy

\section{Introduction}

Friction stir processing (FSP) is a technique derived from friction stir welding (FSW) $[1,2]$ where a tool, consisting of a pin and a shoulder, is plunged into the material, until the shoulder comes in contact with the outside surface of the workpiece. Subsequently, the tool is forced along material while the shoulder remains in contact with the workpiece surface. The pin forces the material to undergo intense plastic deformation, resulting in a refined, homogenized and recrystallized microstructure [1-4]. This microstructural modification has been stated as the reason for improvement in mechanical properties, such as tensile properties and fatigue life [5-10].

The tool geometry plays an important role in the microstructural evolution $[3,11]$ and it is a critical process parameter related to FSPed specimen quality. The threads in the tool pin can generate a complex materials flow, resulting in different heat dissipation zones and varying mechanical properties [12]. The severe stress during the process can, in turn change the tool geometry through wear, and consequently, the material flow during the process [13].

The wear characteristics of the tool in FSP/FSW of aluminum alloys were investigated in a limited number of studies. Prado et al. [14] investigated the tool wear for FSW of 6061+20\% Al203 and reported a severe tool wear, eliminating all the threads of the pin, which can be attributed in part to the high volume loading of abrasive alumina. Zeng et al. [15] reported tool wear during FSW of 6061-T6 aluminum alloy, in which the tool made of H13 tool steel lost most of its threaded profile. The absence of threads resulted in a massive void in the bottom of the stir zone, a structural defect referred to as the tunnel defect.

In another study, Prado et al. [13] reported how the FSW tool wears with weld distance and transverse speed. They reported that for each level of transverse speed investigated, wear reached steady state, i.e., the tool wears to a shape after which there is no wear. Prado et al. [13] referred to this phenomenon as the "self-optimization" of the tool because no process defects were found after steady state has been reached. The purpose of this study was to (i) characterize the wear 
characteristics of an H13 steel tool during FSP of 6061-T6 alloy extrusions, and (ii) determine whether self-optimization occurs in the process.

\section{Materials and Methods}

Extruded bars of a 6061-T6 aluminum alloy with the dimensions $330 \times 25.4 \mathrm{~mm}$, were used in this study. FSP was conducted using a Bridgeport vertical milling machine, with the FSP tool tilted $3^{\circ}$ from $z$-axis toward to the processing direction (+x axis). The tool rotation rate and transverse speed were kept constant at $700 \mathrm{rpm}$ in clockwise direction and $50 \mathrm{~mm} / \mathrm{min}$, respectively. The FSP tool was made of $\mathrm{H} 13$ tool steel with a shoulder diameter of $18 \mathrm{~mm}$. The cylindrical pin had a diameter of $5.9 \mathrm{~mm}$, a length of $5 \mathrm{~mm}$ and M6-threads. Sections of the 6061 alloy extrusions, each $25.4 \mathrm{~mm}$ long, were friction stir processed. A micrometer was used to measure the pin tool diameter, placed in contact with the tool shoulder after cutting each section, in the same spot in every measurement procedure. Additional details about the experiments and resultant microstructures in the aluminum alloys are provided elsewhere [16, 17].

Specimens were cross sectioned using low speed diamond saw, followed by epoxy mounting and traditional metallographic polishing. A Tescan Mira 3 Field Emission Scanning Electron Microscope (FE-SEM) equipped with an Oxford X-Max 50 energy dispersive spectrometer was used to evaluate microstructure on unetched specimens.

\section{Results and discussion}

Wear, defined as the percentage change in the tool diameter with respect to its original diameter, is presented in Figure 1 as a function of the length of the specimen (x) that was FSPed. Note that there is no point where a steady state has been reached, which is in contrast with the findings of Prado et al. Moreover, when a single curve was fitted, systematic error was detected. Consequently, two separate curves were fitted, as shown in Figure 1, showing two distinct phases of tool wear. The best fit curves have the form $\mathrm{Bx}^{\mathrm{m}}$, where $\mathrm{B}$ and $\mathrm{m}$ are empirical constants. The values of $\mathrm{B}$ and $\mathrm{m}$ are for the two phases are presented in Table 1.

Table 1. Constants for tool life and wear for the two phases.

\begin{tabular}{|c|c|c|c|c|}
\hline & $\mathrm{m}$ & $\mathrm{B}$ & $\mathrm{n}$ & $\mathrm{C}$ \\
\hline Phase I & 0.411 & 1.33 & 0.0089 & 12800 \\
\hline Phase II & 0.089 & 2.50 & 0.0029 & 12470 \\
\hline
\end{tabular}




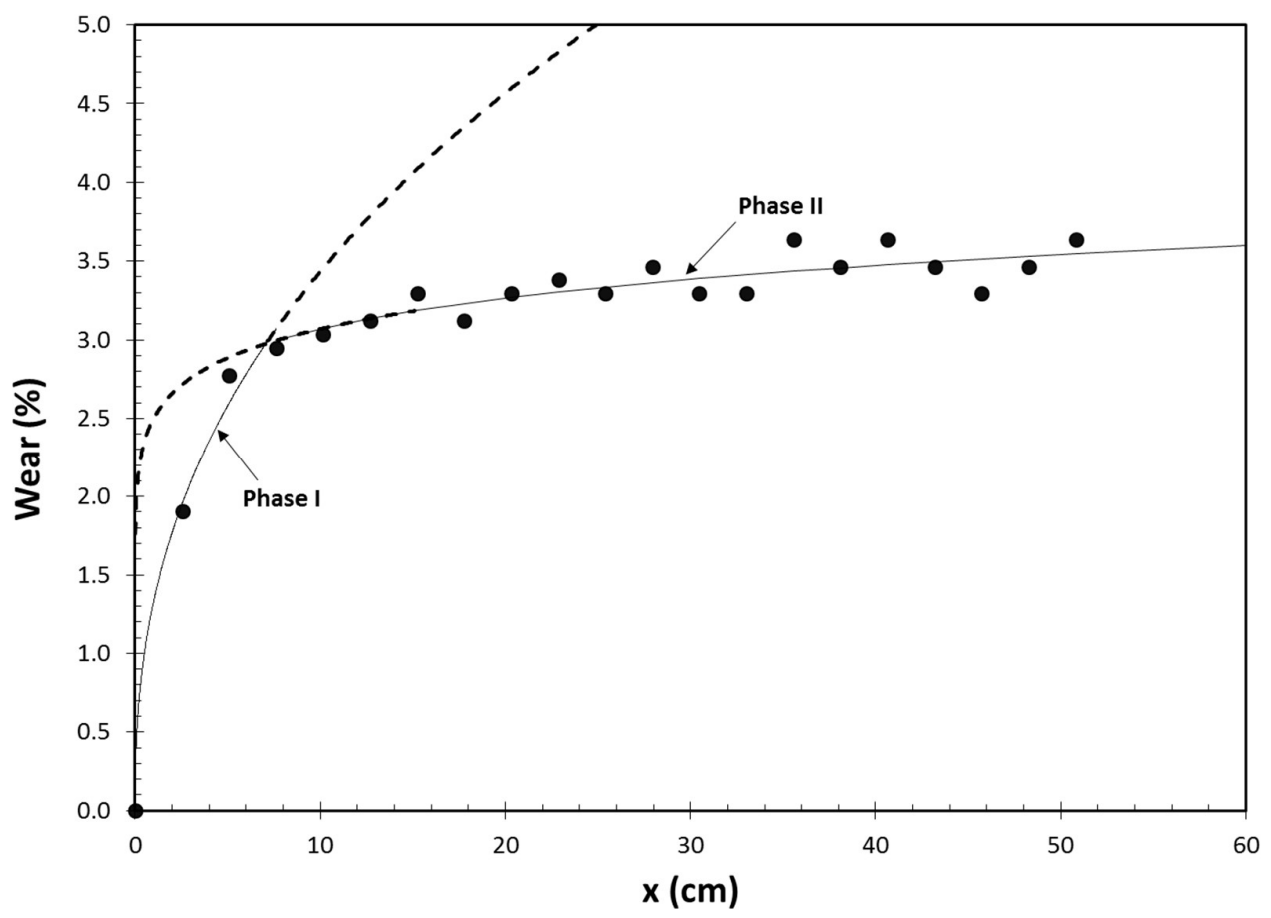

Figure 1. FSP tool wear as a function of the FSPed distance (x), showing two distinct phases.

Tool life in a machining process is described by the well-known Taylor equation [18];

$$
V_{c} t^{n}=C
$$

where $V_{c}$ is the cutting speed $(\mathrm{mm} / \mathrm{min}), t$ is the tool life $(\mathrm{min}), n$ is an exponent that depends on the cutting parameters and $C$ is a constant. To the authors' knowledge, the Taylor equation has not been applied to the characterization of tool wear in FSP. V $\mathrm{V}_{\mathrm{c}}$ can be written in terms of rotational speed, $\omega$, and tool pin diameter, $d_{\text {pin, }}$ as;

$$
V_{c}=\omega \cdot \pi \cdot d_{\text {pin }}
$$

Combining equations (1) and (2) and rearranging the terms, the change in pin diameter with processing time is written as:

$$
d_{\text {pin }}=\frac{C}{\pi \omega t^{n}}
$$

The change in the pin diameter as a function of FSP time is presented in Figure 2. As can be expected, there are two distinct phases at which wear follows different curves. Equation (1) was fitted to the data presented in Figure 2. The Taylor equation parameters for the two phases are also given in Table 1. Although the values of $\mathrm{C}$ for the two phases are not very different, the value of $\mathrm{n}$ is significantly lower in Phase II, indicating a substantially lower wear rate. 


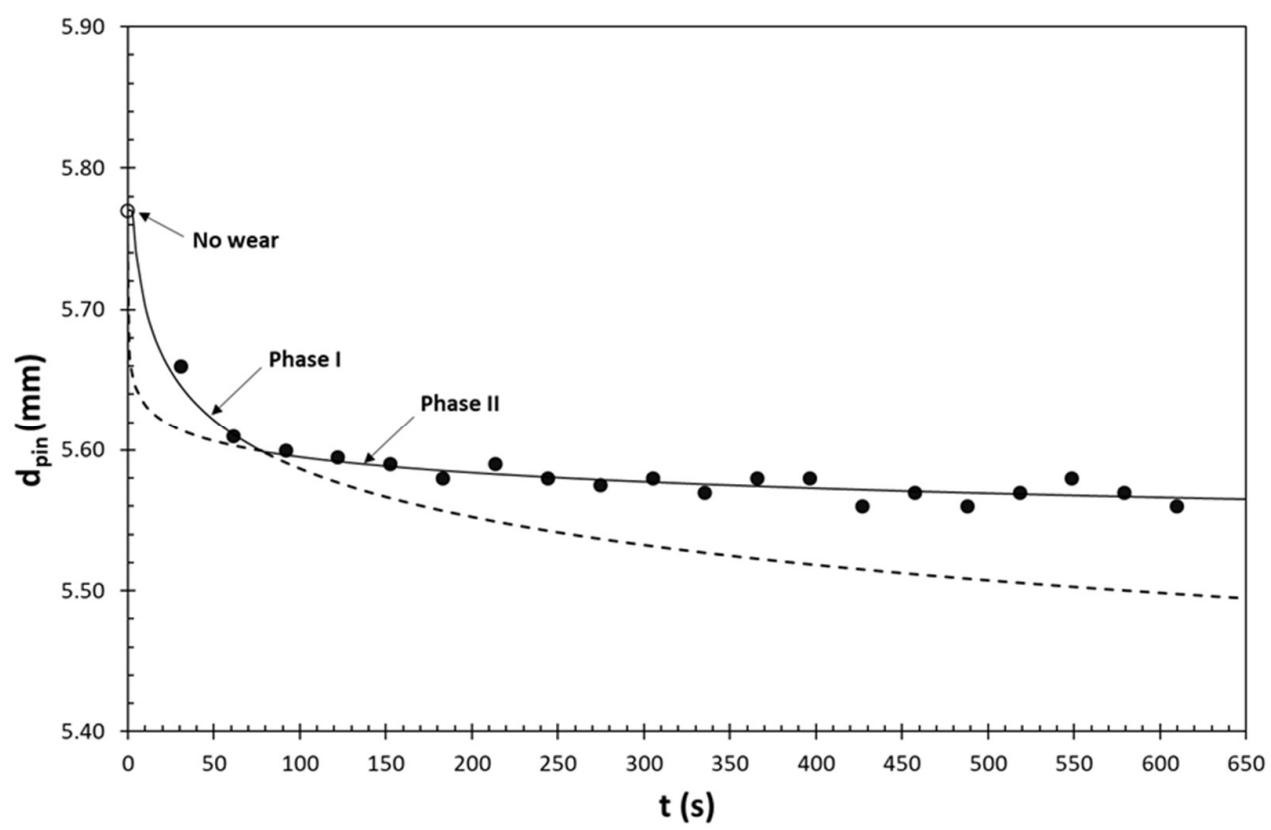

Figure 2. FSP tool diameter described as Taylor equation on Phase I and in a diferent regime after the material depostion, described as Phase II.

To determine the reason for the presence of two distinct phases, the cross sections of three pins were analyzed via scanning electron microscopy (SEM); (i) one tool before FSP (no wear), (ii) one tool used in FSP for 60 seconds $(7.6 \mathrm{~cm}$ ) and (iii) one tool used for 120 seconds $(15.2 \mathrm{~cm})$. SEM images of the cross-sections of the three pins are presented in Figure 3. In Figure 3.a, threads are intact before any FSP. There was severe fracture on the threads within one minute of FSP, as clearly visible in Figure 3.b. Consequently, there was a rapid reduction in diameter, as described at Figure 2. After sixty seconds of FSP, threads were fractured but were not completely eliminated. Therefore, the predominant degradation mechanism at Phase I is found to be the fracture of threads. From 60 to 120 seconds of FSP, wear of threads was visible, Figure 3.c.

It is clear in Figure 3.b and c that aluminum got deposited around the pin, especially between the threads. During FSP, temperature of the material immediately around the FSP tool may approach $500^{\circ} \mathrm{C}[3,19]$. At such high temperatures, the aluminum matrix is quite soft, adheres and gets fused to the steel surface. The deposited material acts similarly to built-up edge (BUE) in machining operations. The formation of a built-up layer during FSP of an aluminum alloy was also observed Sandeep et al. [20]. In machining, the BUE acts as a protective layer during processing [21]. Consequently, the tool diameter shows a very gradual decrease during Phase II in Figure 2. 


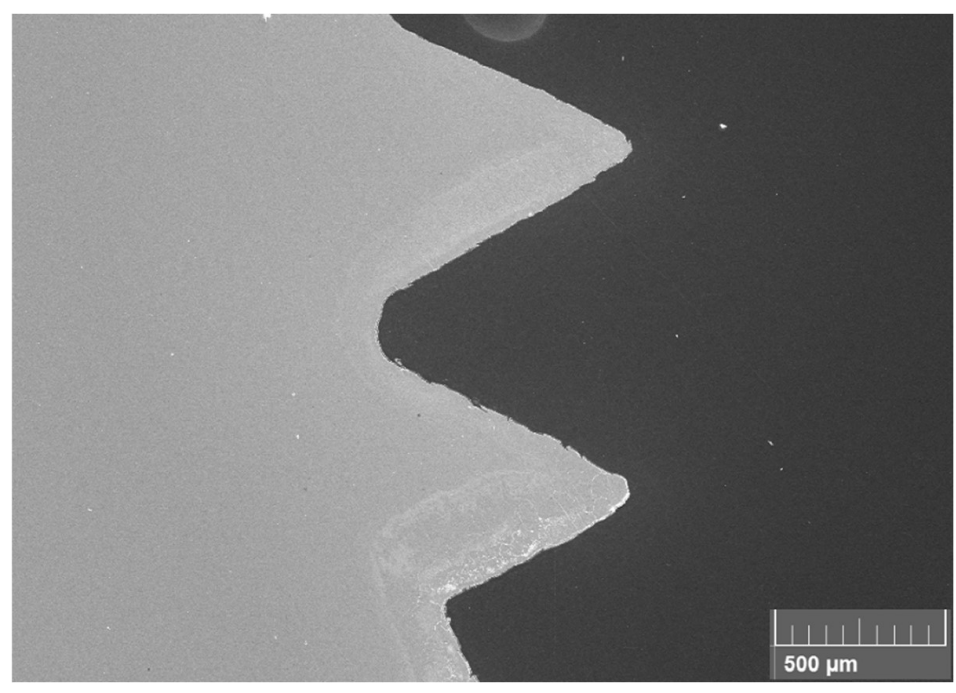

(a)

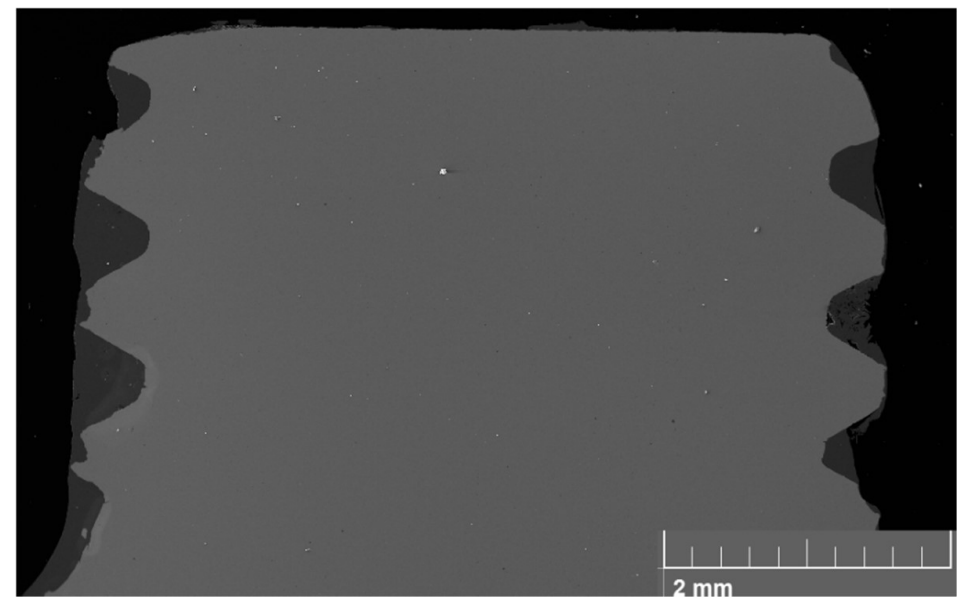

(b)

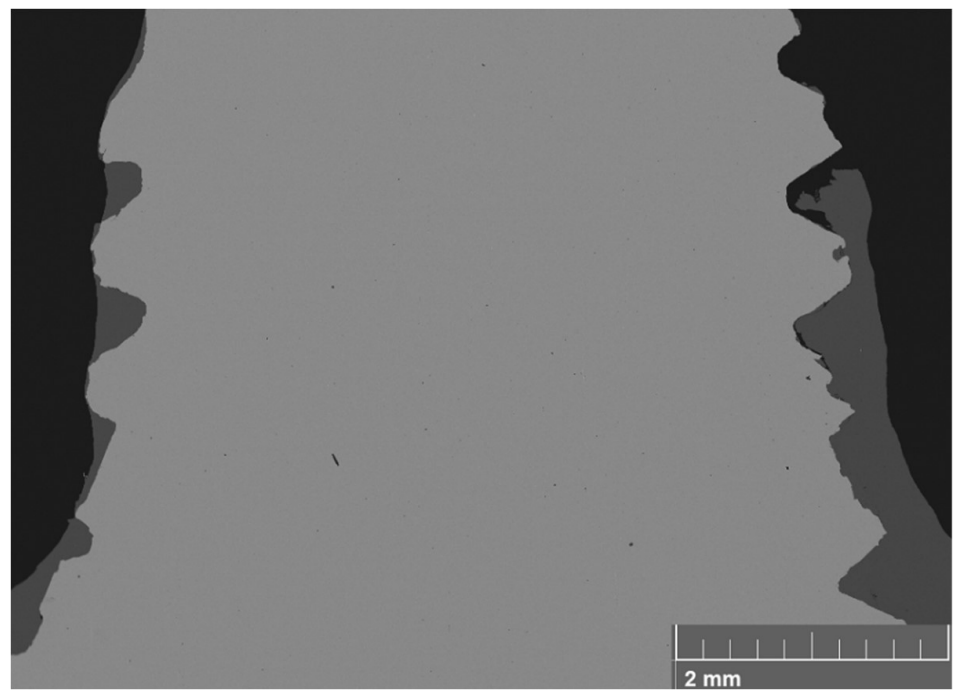

(c)

Figure 3. SEM micrographs of cross sectioned and polished tool threads profile for: (a) no-FSP (unused tool mounted in epoxy) (b) after 60 seconds of FSP, and (c) after 120 seconds of FSP. 
During the experiments, a FSP tool was broken inside a specimen after approximately 70 seconds of processing, i.e., while in the transition from Phase I to Phase II, as described in Figure 2. To determine possible reasons for the tool fracture, the cross-section of the embedded tool was evaluated via SEM. Figure 4 shows the broken tool inside the Al matrix. Note that the tool was fractured in the area between the pin and the shoulder. Moreover, significant deterioration has taken place by fracture of the threads.

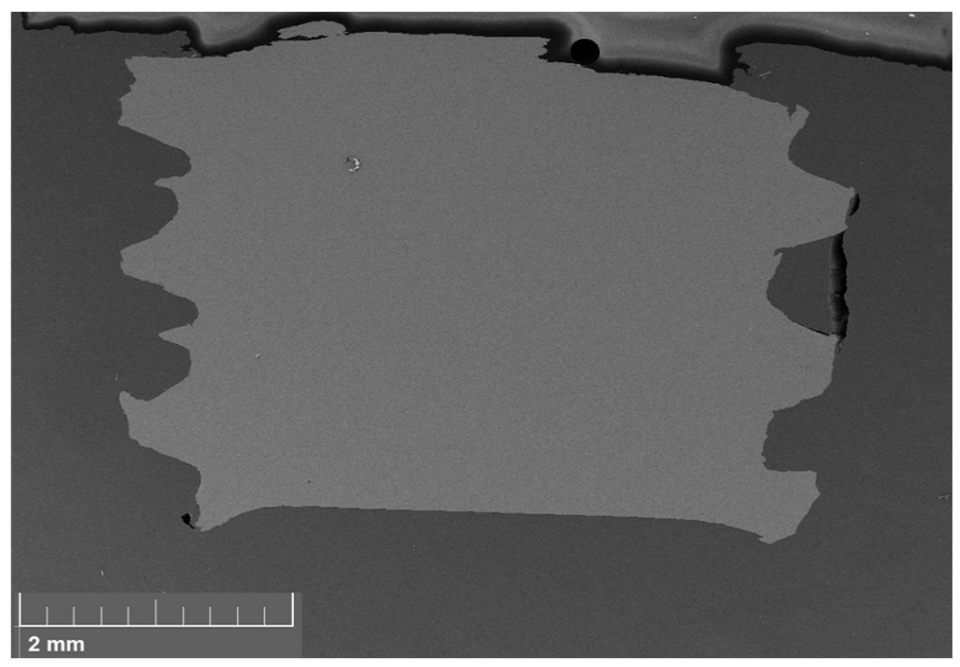

Figure 4. SEM micrograph of a cross section of FSP tool broken inside the Al matrix.

Figure 5 is presents the same cross section as figure 4 , but at higher magnification. This image shows the area between threads, where there is a distinct detachment of aluminum alloy from the bulk material. This area was interpreted as a built-up layer, similar to the BUE formation in machining, as the $\mathrm{Al}$ material is preferentially attaching to the tool, rather than remaining integral to the bulk material. In the same cross section is was also observed that a part of the tool fractured and embedded into the stir zone around the tool, as shown in Figure 6. It is clearly visible that this particle is larger than other particles in the stir zone by several orders of magnitude.

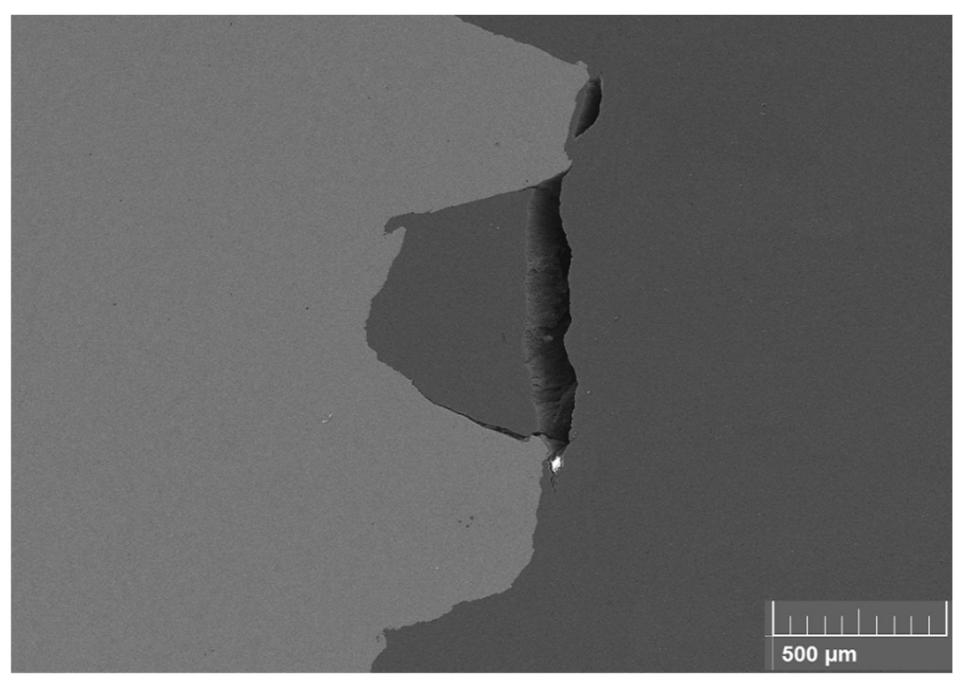

Figure 5. SEM micrograph of the same specimen shown in Figure 4, at higher magnification depeciting the deposition of aluminum between the threads 


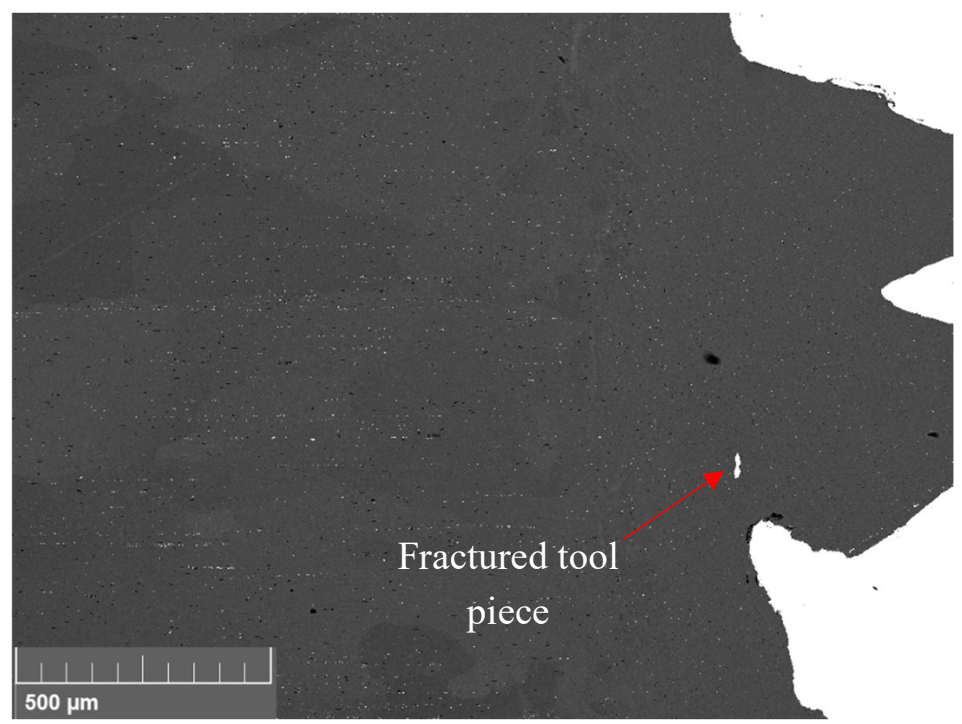

Figure 6. SEM micrograph taken using the backscattered detector showing the presence of a fragment of the tool, embedded in the stir zone of the material.

\section{Conclusions}

- Tool degredation in FSP of 6061-T6 extrusions was found to have two distinct phases. In Phase I, tool degredation is rapid due to fracture of threads of the pin followed a gradual wear in Phase II.

- Layers of processed metal were found to form around the tools, especially between the threads.

- Unlike previous studies, no steady-state in pin diameter was observed.

Author Contributions: The following contributions to this work were made by the following co-authors Conceptualization, MT, NN and PDE; Methodology MT, NN and PDE.; Software, MT, NN.; Validation, MT, NN and PDE, Formal Analysis, NN, MT.; Investigation, NN, PDE.; Resources, MT and PDE.; Data Curation, MT and NN.; Writing-Original Draft Preparation, MT, NN, PDE.; Writing-Review and Editing, MT, NN and PDE.; Visualization, NN, PDE.; Supervision, MT.; Project Administration, MT.; Funding Acquisition, none.

Funding: This research received no external funding.

Acknowledgments: The authors would like to thank Materials Science and Engineering Research Facility (MSERF) at the University of North Florida for the use of sample preparation equipment and the scanning electron microscope.

Conflicts of Interest: The authors declare no conflict of interest. 


\section{References}

[1] R.S. Mishra, M. Mahoney, S. McFadden, N. Mara, A. Mukherjee, High strain rate superplasticity in a friction stir processed $7075 \mathrm{Al}$ alloy, Scripta Materialia, 42 (1999) 163-168.

[2] R.S. Mishra, M.W. Mahoney, Friction stir processing: a new grain refinement technique to achieve high strain rate superplasticity in commercial alloys, in: Materials Science Forum, Trans Tech Publ, 2001, pp. 507-514.

[3] R.S. Mishra, Z.Y. Ma, Friction stir welding and processing, Materials Science and Engineering: R: Reports, 50 (2005) 1-78.

[4] S. Jana, R.S. Mishra, G. Grant, Friction Stir Casting Modification for Enhanced Structural Efficiency: A Volume in the Friction Stir Welding and Processing Book Series, ButterworthHeinemann, 2015.

[5] S. Jana, R.S. Mishra, J.A. Baumann, G.J. Grant, Effect of Friction Stir Processing on Microstructure and Tensile Properties of an Investment Cast Al-7Si-0.6Mg Alloy, Metallurgical and Materials Transactions A, 41 (2010) 2507-2521.

[6] L. Karthikeyan, V. Senthilkumar, K. Padmanabhan, On the role of process variables in the friction stir processing of cast aluminum A319 alloy, Materials \& Design, 31 (2010) 761-771.

[7] M.L. Santella, T. Engstrom, D. Storjohann, T.Y. Pan, Effects of friction stir processing on mechanical properties of the cast aluminum alloys A319 and A356, Scripta Materialia, 53 (2005) 201-206.

[8] Z.Y. Ma, S.R. Sharma, R.S. Mishra, Effect of multiple-pass friction stir processing on microstructure and tensile properties of a cast aluminum-silicon alloy, Scripta Materialia, 54 (2006) 1623-1626.

[9] Z.Y. Ma, S.R. Sharma, R.S. Mishra, Microstructural modification of as-cast Al-Si-Mg alloy by friction stir processing, Metallurgical and Materials Transactions A, 37 (2006) 3323-3336.

[10] S. Jana, R.S. Mishra, J.B. Baumann, G. Grant, Effect of friction stir processing on fatigue behavior of an investment cast Al-7Si-0.6 Mg alloy, Acta Materialia, 58 (2010) 989-1003.

[11] M.S. WĘGLOWSKI, P. SĘDEK, C. HAMILTON, The effect of process parameters on residual stress in a friction stir processed cast aluminium alloy AlSi9Mg, Engineering Transactions, 64 (2016) 301-309.

[12] Z.Y. Ma, Friction Stir Processing Technology: A Review, Metallurgical and Materials Transactions A, 39 (2008) 642-658.

[13] R.A. Prado, L.E. Murr, K.F. Soto, J.C. McClure, Self-optimization in tool wear for friction-stir welding of Al 6061+20\% Al2O3 MMC, Materials Science and Engineering: A, 349 (2003) 156-165. [14] R.A. Prado, L.E. Murr, D.J. Shindo, K.F. Soto, Tool wear in the friction-stir welding of aluminum alloy 6061+20\% Al2O3: a preliminary study, Scripta Materialia, 45 (2001) 75-80.

[15] W.M. Zeng, H.L. Wu, J. Zhang, EFFECT OF TOOL WEAR ON MICROSTRUCTURE, MECHANICAL PROPERTIES AND ACOUSTIC EMISSION OF FRICTION STIR WELDED 6061 Al ALLOY, Acta Metallurgica Sinica (English Letters), 19 (2006) 9-19.

[16] N. Netto, M. Tiryakioğlu, P. Eason, Characterization of Microstructural Refinement and Hardness Profile Resulting from Friction Stir Processing of 6061-T6 Aluminum Alloy Extrusions, Metals, 8 (2018) 552.

[17] N.G.A. Netto, The Effect of Friction Strir Processing on the Microstructure and Tensile Behavior of Aluminum Alloys, MS Thesis, University of North Florida, 2018. 
[18] F.W. Taylor, On the Art of Cutting Metals, American society of mechanical engineers, 1907. [19] M. Mahoney, C. Rhodes, J. Flintoff, W. Bingel, R. Spurling, Properties of friction-stir-welded 7075 T651 aluminum, Metallurgical and materials transactions A, 29 (1998) 1955-1964.

[20] S.K. Singh, R.J. Immanuel, S. Babu, S.K. Panigrahi, G.D. Janaki Ram, Influence of multi-pass friction stir processing on wear behaviour and machinability of an Al-Si hypoeutectic A356 alloy, Journal of Materials Processing Technology, 236 (2016) 252-262.

[21] M.C. Shaw, Metal Cutting Principles, Clarendon Press, 1996. 